\section{AB0453 RED RICE YEAST. AN ALTERNATIVE IN RHEUMATOID ARTHRITIS AND HYPERLIPIDEMIA}

Blanca Varas ${ }^{1}$, María Martín Fuentes ${ }^{2} .{ }^{1}$ Universitary Santa Cristina Hospital, Rheumatology, Madrid, Spain; ${ }^{2}$ Universitary Santa Cristina Hospital, Endocrinology, Madrid, Spain

Background: Lipid profile control is essential in patients diagnosed with inflammatory disease such as rheumatoid arthritis (RA), since cardiovascular events (CV) are still the first cause of mortality. According to the EULAR recommendations on $\mathrm{CV}$ risk, in those patients with a low or moderate CV risk index, for whom diet and exercise have not been effective to diminish low density lipoprotein (LDL) cholesterol below 190 and 100 respectively, we must prescribe a statin. These are the most commonly used drugs with undoubted benefits shown in medical literature. However, often-polymedicated patients may present intolerances or adverse side effects that limit their use. Red rice yeast, whose main active ingredient is monacolin $\mathrm{K}$, has been used in traditional Chinese medicine since $800 \mathrm{AD}$ as a remedy to reduce the total cholesterol level (TC) in blood, LDL and triglycerides (TG). In addition, some studies underline its anti-inflammatory effect and its benefit in patients with inflammatory pathology. In recent years, its use has spread throughout the western world.

Objectives: To evaluate the efficacy of red rice yeast in patients with elevated levels of TC and LDL in rheumatology clinic.

Methods: Prospective study that includes two cohorts of 30 patients with similar demographic characteristics. One cohort with RA patients and the other one without inflammatory disease. Both groups present high levels of TC and LDL. We study the demographic, clinical and lipid levels. A standard dose of red rice yeast is administered to every patient and we evaluate the analytical response after 3 and 6 months of treatment. For the statistical analysis, we used the SPSS program 22.0 version. Quantitative variables are presented as means \pm standard deviation and qualitative variables as percentages. The comparisons between the quantitative variables are made with the Student's T-test. We compared the mean values for each visit with the Anova test. A p $<0.05$ is considered significant.

Results: In the group of patients without inflammatory pathology $(n=30)$, $73 \%$ are women with an average age of $63.9 \pm 7$ years. The mean of baseline TC is $265.2 \mathrm{mg} / \mathrm{dL} \pm 13.7$ and LDL $176.4 \pm 16$. After 3 and 6 months of treatment, a significant decrease in both values was obtained (TC $231 \pm 19$ and $209.8 \pm 19$ F: 26.71 p 0.000 and LDL $143.9 \pm 20$ and $123.6 \pm 19 \mathrm{~F} 22.51 \mathrm{p} 0.000$ )

In the cohort of patients with RA $(\mathrm{n}=30), 66 \%$ were women with an average age of $62.1 \pm 10$. The mean baseline TC is $258.2 \pm 14$ and LDL is $176.7 \pm 10$. After 3 and 6 months of treatment a significant decrease of both values was obtained (TC $224 \pm 24$ and $196.1 \pm 28 \mathrm{~F}$ : 21.55 p 0.000 LDL $149.5 \pm 12$ and $122.4 \pm 25$ F: 28.28 p 0.000)

There were no significant changes in HDL or TG levels. Neither adverse effects were detected nor treatment was abandoned.

Conclusion: The red rice yeast significantly decreases the levels of TC and LDL in the two cohorts. In patients with RA and mild or moderate CV risk, where a close control is necessary, the use of red rice yeast could be an effective therapeutic alternative free of adverse side effects. More studies are needed with a greater number of patients to corroborate these data

\section{REFERENCES}

[1] Agca R, Heslinga SC, Rollefstad S, et al. EULAR recommendations for cardiovascular disease risk management in patients with rheumatoid arthritis and other forms of inflammatory joint disorders: 2015/2016 update Annals of the Rheumatic Diseases 2017;76:17-28.

Disclosure of Interests: None declared

DOI: 10.1136/annrheumdis-2019-eular.7836

\section{$\mathrm{AB} 0454$}

FREQUENCY AND DURATION OF EARLY NON-SERIOUS ADVERSE EVENTS IN RHEUMATOID ARTHRITIS PATIENTS TREATED WITH TOFACITINIB 5 MG TWICE DAILY AS MONOTHERAPY AND COMBINATION THERAPY

Ara Dikraniann ${ }^{1}$, Jürgen Wollenhaupt ${ }^{2}$, Valderilio F. Azevedo ${ }^{3}$, Louis Bessette ${ }^{4}$, David Gold ${ }^{5}$, Jose Luis Rivas ${ }^{6}$, Harry Shi ${ }^{7}$, Lisy Wang ${ }^{8}$, John Woolcott ${ }^{7}$, Andrea Shapiro ${ }^{9}$, Peter Nash ${ }^{10} .{ }^{1}$ Cabrillo Center for Rheumatic Disease, San Diego, CA, United States of America; ${ }^{2}$ Schön-Klinik Hamburg-Eillbek Teaching Hospital of the University of Hamburg, Hamburg, Germany; ${ }^{3}$ Universidade Federal do Paraná, Curitiba, Brazil; ${ }^{4}$ Laval University, Kirkland, QC, Canada; ${ }^{5}$ Pfizer Canada, Montreal, QC, Canada; ${ }^{6}$ Pfizer SLU, Madrid, Spain; ${ }^{7}$ Pfizer Inc, Collegeville, PA, United States of America; ${ }^{8}$ Pfizer Inc, Groton, CT, United States of America; ${ }^{9}$ Pfizer Inc, Peapack, NJ, United States of America; ${ }^{10}$ University of Queensland, Brisbane, Australia

Background: Tolerability remains ill-defined in clinical trials and commonly refers to non-serious adverse events (AEs) impacting patient (pt) satisfaction and treatment adherence. Tofacitinib is an oral JAK inhibitor for the treatment of rheumatoid arthritis (RA).

Objectives: This update to a previously published post hoc analysis ${ }^{1}$ describes the frequency and duration of the most common tolerabilityrelated non-serious AEs in pts with RA receiving tofacitinib $5 \mathrm{mg} B I D$ as monotherapy or with conventional synthetic (cs)DMARDs in Phase (P)3 and P3b/4 studies.

Methods: Data were pooled from: ORAL Step (NCT00960440); ORAL Solo (NCT00814307); ORAL Scan (NCT00847613); ORAL Sync (NCT00856544); ORAL Standard (NCT00853385); and ORAL Strategy (NCT02187055). This post hoc analysis included data from pts receiving tofacitinib $5 \mathrm{mg}$ BID monotherapy (ORAL Solo, ORAL Strategy), placebo (PBO; ORAL Solo), or tofacitinib $5 \mathrm{mg}$ BID or PBO with csDMARDs (all studies except ORAL Solo). Non-serious AEs (affecting pts' day-to-day experience and ability to tolerate therapy) with incidence rates (IRs, pts with events/100 pt-years) $\geq 5$ were evaluated up to Month (M)3. Infections, laboratory test abnormalities, general disorders or events not directly reported by pts, and musculoskeletal disorders likely due to underlying RA, were excluded.

Results: Of the 2657 pts included in the analysis, 1976 received tofacitinib $5 \mathrm{mg}$ BID (monotherapy: $\mathrm{N}=627$; combination: $\mathrm{N}=1349$ ) and 681 received PBO (monotherapy: $\mathrm{N}=122$; combination: $\mathrm{N}=559$ ). The most frequent non-serious $A E s$ up to $M 3$ are shown in the Table. IRs $\geq 10$ were seen for headache and diarrhoea (tofacitinib $5 \mathrm{mg}$ BID monotherapy, combination therapy and PBO monotherapy), and nausea (PBO monotherapy and PBO combination therapy). Non-serious AE duration was $\leq 4$ weeks for most pts with headaches, diarrhoea or gastric discomfort (any gastrointestinal pain, dyspepsia, epigastric discomfort or abdominal discomfort/pain). With tofacitinib $5 \mathrm{mg}$ BID and PBO, respectively, duration of AEs was $\leq 2$ weeks for $43.2 \%$ and $64.7 \%$ of pts with headaches; $66.1 \%$ and $81.3 \%$ with diarrhoea; and $36.2 \%$ and $58.6 \%$ with gastric discomfort Most non-serious AEs were mild/moderate.

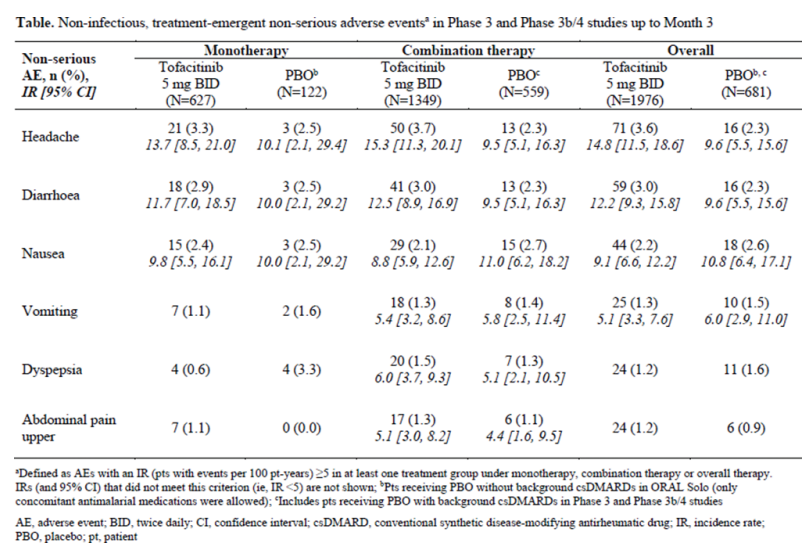

Figure 1 
Conclusion: Overall, non-infectious non-serious AEs were mild/moderate and the majority were self-limiting. Non-serious AE frequency was similar for tofacitinib monotherapy and combination therapy, and for tofacitinib and PBO.

\section{REFERENCES}

[1] Dikranian A, et al. Arthritis Rheumatol 2013; 65: S192.

Acknowledgement: Study sponsored by Pfizer Inc. Medical writing support was provided by Anthony G McCluskey of CMC Connect and funded by Pfizer Inc.

Disclosure of Interests: Ara Dikranian Consultant for: AbbVie, Pfizer Inc, Speakers bureau: AbbVie, Pfizer Inc, Jürgen Wollenhaupt Grant/research support from: Pfizer Inc, Consultant for: Pfizer Inc, Speakers bureau: Pfizer Inc, Valderilio F Azevedo Grant/research support from: AbbVie, GSK, Janssen, Merck Serono, Novartis, Pfizer Inc, UCB, Consultant for: AbbVie, GSK, Janssen, Merck Serono, Novartis, Pfizer Inc, UCB, Louis Bessette Grant/research support from: AbbVie, Amgen, Bristol-Myers Squibb, Celgene, Eli Lilly, Janssen, Novartis, Pfizer Inc, Roche, Sanofi, UCB, Consultant for: AbbVie, Celgene, Eli Lilly, Novartis, Pfizer Inc, David Gold Shareholder of: Pfizer Inc, Employee of: Pfizer Inc, Jose Luis Rivas Shareholder of: Pfizer Inc, Employee of: Pfizer Inc, Harry Shi Shareholder of: Pfizer Inc, Employee of: Pfizer Inc, Lisy Wang Shareholder of: Pfizer Inc, Employee of: Pfizer Inc, John Woolcott Shareholder of: Pfizer Inc, Employee of: Pfizer Inc, Andrea Shapiro Shareholder of: Pfizer Inc, Employee of: Pfizer Inc, Peter Nash Grant/research support from: AbbVie, Bristol-Myers Squibb, Eli Lilly, Janssen, Novartis, Pfizer Inc, Roche, Sanofi, UCB, Consultant for: AbbVie, Bristol-Myers Squibb, Eli Lilly, Janssen, Novartis, Pfizer Inc, Roche, Sanofi, UCB, Speakers bureau: AbbVie, Bristol-Myers Squibb, Eli Lilly, Janssen, Novartis, Pfizer Inc, Roche, Sanofi, UCB

DOI: 10.1136/annrheumdis-2019-eular.418

\section{AB0455 FACTORS ASSOCIATED WITH DAS28 RESPONSE IN BIOLOGIC-NAIIVE PATIENTS WITH RHEUMATOID ARTHRITIS: 10 YEAR FOLLOW-UP}

Daniel Xavier Xibille Friedmann ${ }^{1}$, Maricela Escobar Román ${ }^{2}$, Sandra Miriam Carrillo Vazquez ${ }^{3}$, José Luis Montiel Hernández ${ }^{4} .{ }^{1}$ Hospital General de Cuernavaca, SSM, Rheumatology, Cuernavaca, MOR, Mexico; ${ }^{2}$ Universidad Latinoamericana, School of Medicine, Cuernavaca, MOR, Mexico; ${ }^{3} \mathrm{Hospital} 1$ de Octubre, ISSSTE, Rheumatology, Mexico, Mexico; ${ }^{4}$ Universidad Autónoma del Estado de Morelos, Faculty of Pharmacy, Cuernavaca, Mexico

Background: Access to adequate care is limited in Mexico as biologics or targeted therapies are unavailable for a proportion of patients with rheumatoid arthritis (RA) and only methotrexate and other conventional (c) DMARDs are employed as therapeutic options in many cases.

Objectives: To determine the factors associated to DAS28 response in patients with rheumatoid arthritis followed up to 10 years and who never received biologic or targeted therapy, being treated only with cDMARDs. Methods: We analyzed a prospective cohort of 543 patients with RA followed for 10 years (March 2006 to February 2016) at the Hospital General de Cuernavaca, in central México. Demographic data, shared epitope (SE; HLA-DR*0101, *0102, *0401, ${ }^{*} 0404,{ }^{*} 0405, \quad{ }^{*} 0408, \quad{ }^{*} 0410, \quad{ }^{*} 1001$, *1402) status, date since onset of disease and treatment, clinical and disease activity characteristics as well as treatment data was obtained and followed through time. Patients were seen by a rheumatologist every three months and blood samples obtained on each visit. The DAS28 score was determined on each visit and treatment adjusted accordingly. They were treated with prednisone (PDN; $\leq 10 \mathrm{mg} /$ day), Methotrexate (MTX; 7.5-25 mg/week), Cloroquine (CLQ; 150-300 mg/day), Sulphasalazine (SSZ; $1-3 \mathrm{gr} /$ day) or a combination of these. Descriptive statistics were used for the analysis of demographic data and parametric correlation tests (Spearman) were employed in the analysis.

Results: Of the $543,94.3 \%$ of patients were women; mean age at baseline was 54.1 years (23-89; SD 12.4), mean time since onset of disease was 6.6 years $(0-49 ; S D 7.9)$ and mean time since onset of treatment was 3 years (1-9; SD 2.12). HLA was determined in 57 patients and $36.8 \%$ of these patients were SE positive (one or two alleles). Most patients received treatment on the baseline visit based mainly on MTX (72.7\%) combined with CLQ (63\%) and low-dose PDN (76.4\%). Less than $5 \%$ was under treatment with a non-MTX cDMARD. Baseline mean DAS28 was 4.9 (0.9-8.3; SD 1.41). At 6 months since DMARD-onset mean DAS28 was $3.8(0.42-8.0 ;$ SD 1.46$)$, at 12 months mean DAS28 was 3.6 (0.14-7.6; SD 1.34). At 2 years of follow-up, mean DAS28 remained at $3.6(1.27-7.43 ;$ SD 1.35). Over the course of the next 8 years patients maintained a mean DAS28 between 3.5-3.6, with no significant changes in spite of continuing CDMARD treatment. Apart from being under treatment, which correlated with a better DAS28 score, being female correlated with a poorer DAS28 response $(p<0.05)$. The other baseline factor significantly associated to an improved long-term outcome regarding disease activity was time since onset of disease, which correlated with a higher DAS28 score during the first two years of follow up but tapered after two years of follow-up $(p<0.001)$. One of the limitations of the study was the significant drop-out rate $(>20 \%)$ seen during follow up.

Conclusion: DAS28 response occurs mainly in the first 2 years of treatment. After that, cDMARD treatment is associated to a stationary effect over DAS28 in patients with no access to biologics or targeted therapies. This is an important factor to consider when establishing long-term therapeutic strategy from a cost-effective point of view.

\section{REFERENCES}

[1] Hazlewood, G. S. et al. Methotrexate monotherapy and methotrexate combination therapy with traditional and biologic disease modifying antirheumatic drugs for rheumatoid arthritis: abridged Cochrane systematic review and network meta- analysis. BMJ 353, i1777(2016).

[2] Salliot, C. \& van der Heijde, D. Long-term safety of methotrexate monotherapy in patients with rheumatoid arthritis: a systematic literature research. Ann. Rheum. Dis. 68, 1100-1104 (2009).

Disclosure of Interests: Daniel Xavier Xibille Friedmann Consultant for: Lilly, Abbvie, BMS, Speakers bureau: Lilly, Abbvie, Maricela Escobar Román: None declared, Sandra Miriam Carrillo Vazquez Consultant for: Roche, Lilly, BMS, Speakers bureau: Roche, Lilly, Abbvie, BMS, José Luis Montiel Hernández Grant/research support from: Pfizer DOI: 10.1136/annrheumdis-2019-eular.4304

\section{AB0456 PERCEPTIONS OF GLUCOSTEROID SIDE EFFECTS IN RHEUMATOID ARTHRITISPATIENTS}

Saoussen Miladi, Makhlouf yasmine, Alia Fazaa, Selma Chekili, Salma Kassab, Kmar Ouenniche, Leila Souebni, Kaouther Ben Abdelghani, Ahmed Laatar. Mongi Slim Hospital, Tunis, Tunisia

Background: Most of the new recommendations proposed for the management of Rheumatoid arthritis (RA) emphasize the involvement of patients in therapeutic decision-making. This should encourage us to evaluate their level of information, fears and beliefs about the different treatments especially corticosteroids.

Objectives: The aim of this study was to evaluate the fears and beliefs of Tunisian patients with RA regarding corticosteroids.

Methods: A prospective study including 35 RA patients according to the ACR/EULAR 2010 criteria was performed. All of them were treated with corticosteroid therapy in addition to DMARDs and their usual long-term treatment. Every patient included in the study completed a questionnaire, containing sociodemographic component and evaluating corticosteroid modality use as well as side effects[1].

Results: The study included 35 patients with female predominance $(74$ $3 \%)$. The mean age was 57 years (29-72). The mean duration of the disease was 8 years (2-13 years). All RA patients were immunopositive for rheumatoid factor and/or for Anti-cyclic citrullinated peptide antibody (antiCCP). Twenty-six patients were on Methotrexate, 6 on Infliximab, and 3 on Rituximab. Corticosteroid therapy was prescribed at a mean dose of $7.5 \mathrm{mg}$ prednisone (5 to $10 \mathrm{mg}$ ). The level of education of our patients was generally low: 17 were illiterate, 10 had received a primary or secondary education, only 8 attended college. None of them was part of a medical or paramedical profession. Twenty patients, of whom eight diabetic, had an idea about the potentially harmful effect of corticosteroids on glycemic equilibrium (14 patients reported hyperglycemia and six patients mentioned hypoglycemia). Forty percent were aware of obesity as an effect correlated with corticotherapy. Moreover, $34.3 \%$ of patients talked about the hypertensive peak as a serious complication. Osteoporosis was mentioned in $17.1 \%$ of cases. About 10 patients had no idea about the adverse effects of steroids. When asking them about their source of information: they mentioned respectively television and radio programs with medical informative content, environment and medical or paramedical medical staff.

Conclusion: This study highlights the insufficiency of the level of information provided for RA patients regarding corticosteroids side effects. New awareness-raising materials should be reinforced and adapted to make full use of their potential with less likelihood of adverse effects. 